\title{
Molecular Cytogenetics of Pisum sativum L. Grown under Spaceflight-Related Stress
}

\author{
Olga Yu. Yurkevich $\mathbb{D}^{1},{ }^{1}$ Tatiana E. Samatadze, ${ }^{1}$ Margarita A. Levinskikh, ${ }^{2}$ \\ Svyatoslav A. Zoshchuk, ${ }^{1}$ Olga B. Signalova, ${ }^{2}$ Sergei A. Surzhikov, ${ }^{1}$ Vladimir N. Sychev, ${ }^{2}$ \\ Alexandra V. Amosova $\mathbb{D}^{1}{ }^{1}$ and Olga V. Muravenko $\mathbb{D}^{1}$ \\ ${ }^{1}$ Engelhardt Institute of Molecular Biology, Russian Academy of Sciences, 119991 Moscow, Russia \\ ${ }^{2}$ Institute of Biomedical Problems, Russian Academy of Sciences, 123007 Moscow, Russia \\ Correspondence should be addressed to Olga V. Muravenko; olgmur1@yandex.ru
}

Received 21 September 2018; Revised 26 October 2018; Accepted 22 November 2018; Published 6 December 2018

Guest Editor: Yuri Shavrukov

Copyright (C) 2018 Olga Yu. Yurkevich et al. This is an open access article distributed under the Creative Commons Attribution License, which permits unrestricted use, distribution, and reproduction in any medium, provided the original work is properly cited.

\begin{abstract}
The ontogenesis and reproduction of plants cultivated aboard a spacecraft occur inside the unique closed ecological system wherein plants are subjected to serious abiotic stresses. For the first time, a comparative molecular cytogenetic analysis of Pisum sativum L. (Fabaceae) grown on board the RS ISS during the Expedition-14 and Expedition-16 and also plants of their succeeding (F1 and F2) generations cultivated on Earth was performed in order to reveal possible structural chromosome changes in the pea genome. The karyotypes of these plants were studied by multicolour fluorescence in situ hybridization (FISH) with five different repeated DNA sequences ( $45 \mathrm{~S}$ rDNA, $5 \mathrm{~S}$ rDNA, PisTR-B/1, microsatellite motifs $(\mathrm{AG})_{12}$, and (GAA) $)_{9}$ ) as probes. A chromosome aberration was revealed in one F1 plant. Significant changes in distribution of the examined repeated DNAs in karyotypes of the "space grown" pea plants as well as in F1 and F2 plants cultivated on Earth were not observed if compared with control plants. Additional oligo$(\mathrm{GAA})_{9}$ sites were detected on chromosomes 6 and 7 in karyotypes of F1 and F2 plants. The detected changes might be related to intraspecific genomic polymorphism or plant cell adaptive responses to spaceflight-related stress factors. Our findings suggest that, despite gradual total trace contamination of the atmosphere on board the ISS associated with the extension of the space station operating life, exposure to the space environment did not induce serious chromosome reorganizations in genomes of the "space grown" pea plants and generations of these plants cultivated on Earth.
\end{abstract}

\section{Introduction}

The presence of growing plants aboard a spacecraft is important for creating and supporting a sustainable living environment during long-term space missions, and in the near future plant systems will become important components of any long-duration exploration scenario. At the same time, the ontogenesis and reproduction of plants occur inside the unique closed ecological system wherein plants undergo serious abiotic stress which can be induced by a number of factors including changes in gravity, radiations, vibration, aboard air composition with limited exchange of gases, humidity, nutrients, temperature, and light. They are often associated with reprogramming of gene expression and can influence plant growth, development, and yield [1-3]. Specifically, seed size reduction was observed in Arabidopsis thaliana (L.) Heynh, Brassica rapa L., and Triticum aestivum L. grown for full life cycles under microgravity conditions aboard the International Space Station (ISS) [4-7]. Changes in the cell wall metabolism were revealed in A. thaliana cultivated under microgravity conditions in space [8]. In Hordeum vulgare L., A. thaliana, and B. rapa, overexpression of some genes associated with stress response proteins (heat shock proteins (HSP), pathogenesis-related proteins, and antioxidant proteins) was detected under space environment [9-12]. Besides, differential organ-specific proteome responses to spaceflight environment were revealed in leaves and roots from $A$. thaliana [13]. Also, chemical contamination of the artificial atmosphere aboard a spacecraft can influence the growth and development of plants cultivated there $[1,5,14]$. 
The "Lada" space greenhouse installed inside the Russian Segment of the International Space Station (RS ISS) provides optimal conditions for plant growth and development $[15,16]$. It was shown that plants of Pisum sativum L. (Fabaceae) cultivated in the "Lada" greenhouse during four successive expeditions (Expeditions-7-Expeditions-10) maintained their reproductive functions and viable seeds for four full life cycles [17]. Analysis of genetic polymorphism by random amplified polymorphic DNA (RAPD) did not reveal changes in "space" plants compared to the ground control $[17,18]$. In karyotypes of these "space" samples, significant chromosomal rearrangements were also not detected though polymorphic organization of constitutive heterochromatin (C-band polymorphism) was observed [19]. However, the results of the 15-year monitoring of volatile organic compounds in the air onboard the ISS demonstrated that, with the extension of the space station operating life, the total chemical contamination gradually built up and diversity and toxicity of the compounds increased [20]. Over time, this process can influence the ontogenesis of the plants cultivated there and/or induce changes (e.g., chromosome aberrations) in their genomes $[1,5,14]$.

In eukaryotes, heterochromatin plays a key role in epigenetic regulation of gene expression. It was shown that heterochromatin gives rise to small interfering RNAs (siRNAs) derived from transposable elements or DNA repeats [21, 22]. In plants, heterochromatic siRNAs are the most abundant class of small RNAs which play important roles in gene regulation by means of RNA-directed DNA methylation [22-25]. Environmental stress factors can induce structural changes in heterochromatin $[22,26]$. C-heterochromatin comprises different repeated DNA sequences including highly repeated (satellite) DNA, transposable elements and also microsatellites, or simple sequence repeats (SSRs) which consist of tandem duplications of 1-6 bp motifs [27, 28]. Microsatellites play diverse functional roles in eukaryotic genome (e.g., modulation of gene expression, regulation of chromatin organization, DNA metabolic processes, and RNA structure) [29]. Besides, SSRs are effective genetic markers due to their common length polymorphism, and they are widely used in genetic studies [30]. Microsatellites in coding sequences can be directly linked to gene function, and mutations in microsatellites may induce the functional genomic changes providing a basis for quick adaptations to environmental changes [31-33].

The rRNA genes can serve as excellent markers in phylogenetic and cytogenetic studies of plants. These genes are organized into two distinct families (i.e., 45S and 5S rDNA) that occur as tandem repeat arrays at specific chromosomal regions. Due to high copy number, detection of rDNAs is highly reproducible and provides valuable information concerning chromosomal evolution [34]. In plant genomes, the copy numbers and chromosomal distribution of rDNAs can vary rapidly even within intraspecific taxa and can therefore provide chromosomal landmarks for genome plasticity [3436].

Thus, DNA repeated sequences play a significant role in plant genome adaptation to stress factors, and therefore it is important to investigate the karyotype polymorphism and chromosomal distribution of these DNA fractions in plants cultivated aboard a spacecraft. In the present study, molecular cytogenetic characterization of $P$. sativum plants grown on board the RS ISS during Expedition-14 and Expedition16 (ISS-14 and ISS-16) and also plants of the succeeding generations cultivated on Earth was performed in order to reveal possible chromosome changes in the $P$. sativum genome. The karyotypes of these plants were studied by multicolour fluorescence in situ hybridization (FISH) with five different repeated DNA sequences (45S rDNA, 5S rDNA, PisTR-B/1, microsatellite motifs $(\mathrm{AG})_{12}$, and $(\mathrm{GAA})_{9}$ ) as probes.

\section{Materials and Methods}

2.1. Plant Material. Seeds of line 131 of $P$. sativum $(2 \mathrm{n}=14)$ (generation F0) were obtained from the collection of Department of Biology of M.V. Lomonosov Moscow State University [18].

During the ISS Expedition-14 and Expedition-16, these seeds (generations F0-14 and F0-16, correspondingly) were grown in the Lada space greenhouse installed inside the RS ISS [17]. The seeds were germinated after irrigation with water, and the seedlings were cultivated in Lada at $23 \pm$ $1^{\circ} \mathrm{C}$ and 40 to $50 \%$ humidity under $24 \mathrm{~h}$ lighting. Fluorescent bulbs of the lighting unit generate photosynthetically active radiation with the flux at the root module surface of $250 \mu \mathrm{mol} \mathrm{m}^{-2} \mathrm{~s}^{-1}$ minimum at a distance of $150 \mathrm{~mm}$ away from the light emitting surface. The moisture supply to the substrate was controlled at a constant, optimal level by the Lada system using in situ moisture sensors. The substrate consisted of the porous ceramic soil conditioner Turface (Profile Products, Buffalo Grove, IL) fertilized with Osmocote (14N-14P-14K) (Scotts Professional, Geldermalsen, Netherlands).

During the ISS-14, the experiment was being carried out for 78 days (11/01/2007-13/04/2007) by a flight engineer $M$. Tyurin. During the ISS-16, the experiment was being carried out for 79 days (10/01/2008-13/04/2008) by a flight engineer Yu. Malenchenko. After completion of each experiment, the seedpods with the "space grown" seeds (F1 generations (F1-14 and F1-16)) were harvested and transported back to Earth for further analyses.

The "space grown" seeds were stored until use under aseptic conditions at $3-4^{\circ} \mathrm{C}$ and a relative humidity of 13-14\% which enabled successful long-term seed storage $[37,38]$.

Then "space grown" seeds were germinated and used for chromosome spread preparation and also further postflight planting (F2 generations (F2-14 and F2-16)). The seeds of line 131 cultivated only on Earth were used as a control. Ground control and postflight cultivation were carried out using the same substrate and similar greenhouse and at the same conditions.

2.2. Chromosome Slide Preparation. For FISH, the modified technique of chromosome spread preparation from pea root tips was applied [39]. The seeds were germinated in Petri 
dishes on the moist filter paper at room temperature. Root tips (of $0.5 \mathrm{~cm}$ ) were excised and treated overnight (16$20 \mathrm{~h}$ ) in ice-cold water. After the pretreatment, the root tips were fixed in ethanol:acetic acid (3:1) for 3-24h at room temperature. Before squashing, the roots were transferred into $1 \%$ acetocarmine solution in $45 \%$ acetic acid for $15 \mathrm{~min}$. The cover slips were removed after freezing in liquid nitrogen. The slides were dehydrated in $96 \%$ ethanol and then air-dried.

\subsection{DNA Probe Preparation. The following probes were used for FISH:}

(1) pTa71: a 9-kb-long sequence of common wheat encoding 18S, 5.8S, and 26S rRNA genes including spacers [40]. This DNA probe was labelled directly with SpectrumAqua and SpectrumRed fluorochromes (Abbott Molecular, Wiesbaden, Germany) by nick translation according to manufacturers' protocols.

(2) pTa794: a 420-bp-long sequence of wheat containing the 5S rRNA gene and intergenic spacer [41]. This DNA probe was labelled directly with SpectrumRed fluorochrome (Abbott Molecular, Wiesbaden, Germany) by nick translation according to manufacturers' protocols.

(3) The oligo-(GAA) ${ }_{9}$ probe labelled with fluorescein12-dUTP (Roche Diagnostics, Mannheim, Germany) and oligo-(AG) 12 probe labelled with Cy3-dUTP (DNA Synthesis, Moscow, RF). These probes were synthesized using a synthesizer ABI 394 (Applied BioSystems, Redwood City, USA) in the laboratory of biological microchips of Engelhardt Institute of Molecular Biology of RAS, Moscow, RF.

(4) The PisTR-B/1 repeat sequence (GenBank number AF300830.1) (Invitrogen, California, USA) used for identification of $P$. sativum chromosomes [42]. This DNA probe was labelled directly with fluorochromes PlatinumBright 415 and PlatinumBright 495 by Nucleic Acids Labeling Kits (Kreatech Diagnostics, Amsterdam, Netherlands) according to manufacturers' protocols.

2.4. FISH Procedure. Before FISH procedure, chromosome slides were pretreated with $1 \mathrm{mg} / \mathrm{ml}$ of RNase A (Roche Diagnostics, Mannheim, Germany) in $2 x S S C$ at $37^{\circ} \mathrm{C}$ for $1 \mathrm{~h}$ and then washed three times for $10 \mathrm{~min}$ in $2 \mathrm{xSSC}$. The slides were dehydrated in a series of $70 \%, 85 \%$, and $96 \%$ ethanol solutions and then air-dried. The hybridisation mixture $(22 \mu \mathrm{l})$ containing $40 \mathrm{ng}$ of each labelled probe was added to each slide. Coverslips were placed on the slides and sealed with rubber cement. Slides with DNA probes were codenatured at $74^{\circ} \mathrm{C}$ for $5 \mathrm{~min}$, placed in a moisture chamber, and hybridised overnight at $37^{\circ} \mathrm{C}$. After removing the coverslips, the slides were washed with $0.1 \mathrm{xSSC}$ at $44^{\circ} \mathrm{C}$ for $8 \mathrm{~min}$ and with $2 \mathrm{xSSC}$ at $44^{\circ} \mathrm{C}$ for $8 \mathrm{~min}$ with the final $5 \mathrm{~min}$ wash in $2 \mathrm{xSSC}$ at room temperature. For oligo-(GAA) ${ }_{9}$ probe labelled with fluorescein-12-dUTP, fluorescent signal amplification using FITC-Alexa 488 antibodies (VectorLabs, Youngstown, USA) was performed. After incubation for $60 \mathrm{~min}$ at $37^{\circ} \mathrm{C}$ with the detection mixture, the slides were washed two times with $2 \mathrm{xSSC}$ for $5 \mathrm{~min}$ and once in $1 \mathrm{xPBS}$ for $5 \mathrm{~min}$ each at room temperature. The slides were dehydrated and air-dried in the dark. After FISH procedure, the slides were stained with $0.125 \mu \mathrm{g} / \mathrm{ml}$ DAPI (Serva, Heidelberg, Germany) dissolved in Citifluor anti-fade solution (UKC Chem. Lab., Canterbury, UK).

2.5. Chromosome Analysis. For identification of pea chromosomes, we used the molecular cytogenetic marker PisTR-B/1, developed earlier for cytogenetic classification of $P$. sativum in which the chromosome numbering was brought in line with the genetic (linkage group) identification [43, 44]. For investigation of possible chromosomal polymorphism, the oligonucleotide $(A G)_{12}$ and $(\mathrm{GAA})_{9}$ probes were used for F1 and F2 plants (ISS-14 and 16). At least 8-10 individual plants from each specimen (control, F1, and F2 plants (ISS14 and ISS-16)) were used for the karyotype analyses. At least 15 metaphase plates from each individual were analyzed. The slides were examined using an Olympus BX-61 epifluorescence microscope (Olympus, Tokyo, Japan). Images were captured with monochrome charge-coupled device camera (Cool Snap, Roper Scientific, Inc., Sarasota, FL, USA). Then they were processed with Adobe Photoshop 10.0 software (Adobe, Birmingham, USA).

\section{Results}

3.1. Plant Vegetation Period and External Features of the Plants. The experiment carried out during the ISS-14 showed that the plant vegetation period was about 80 days which was 10-12 days longer than it had been observed in the control ground experiments. This period of the seed-to-seed cycle was found to increase due to slower initial vegetation stages. The experiment carried out during ISS-16 showed that the plant vegetation period was about 65-70 days which was roughly comparable with the results of the control ground experiments. External features of the plants did not differ essentially from the control specimens (Figure 1).

3.2. Chromosomal Markers Revealed by FISH. For the first time, a comparative molecular cytogenetic analysis of pea plants grown on board the RS ISS during the Expedition14 and Expedition-16 and also their succeeding (F1 and F2) generations cultivated on Earth was performed using multicolour FISH with five different repetitive DNAs (45S rDNA, 5S rDNA, the PisTR-B/1 repeat, microsatellite motifs $(\mathrm{AG})_{12}$, and $\left.(\mathrm{GAA})_{9}\right)$.

In karyotypes of all studied $P$. sativum specimens, FISH procedure revealed $45 \mathrm{~S}$ rDNA sites in the distal regions of the long arms of the satellite chromosome pairs 4 and 7 . These chromosomes pairs can easily be distinguished as a larger satellite and a larger site of $(\mathrm{GAA})_{9}$ was revealed on chromosome 7 than on chromosome 4 (Figures 2 and 3 ).

Hybridization sites of $5 \mathrm{~S}$ rDNA were detected in three chromosome pairs: in the subtelomere region of the short arm of chromosome 1, in the subtelomere region of the short arm of chromosome 3 (colocalized with a large site of the oligo$(\mathrm{AG})_{12}$ probe), and also in the median region of the short arm of chromosome 5 (Figures 2 and 3 ). 


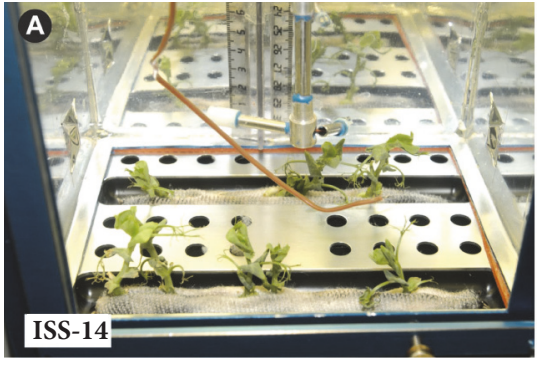

(a)

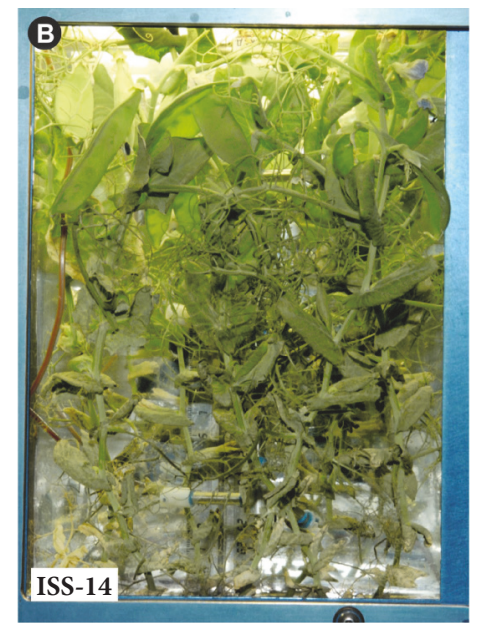

(b)

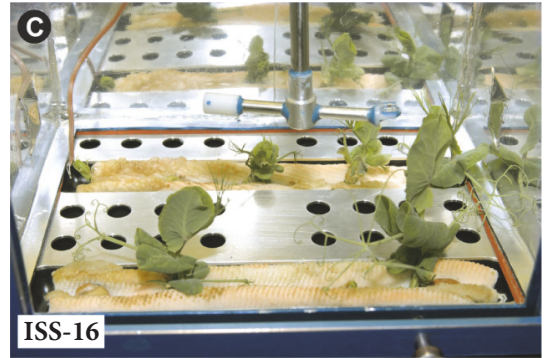

(c)

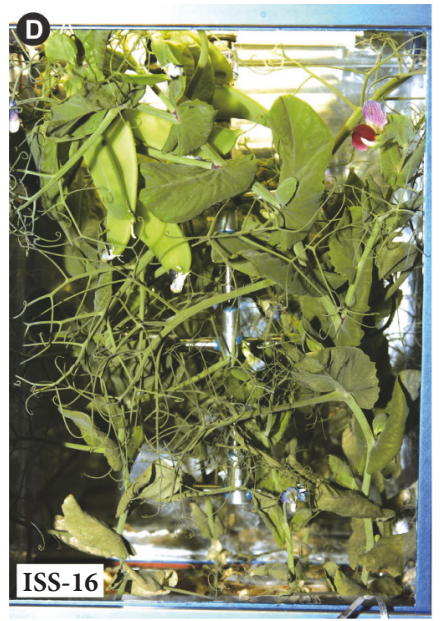

(d)

FIGURE 1: P. sativum plants in the Lada greenhouse aboard the RS ISS. Initial vegetation stages of pea plants were longer during the ISS-14 (a) compared to the ISS-16 (c). Adult plants came into flower and formed seedpods during both the ISS-14 (b) and ISS-16 (d).

The PisTR-B/1 repeat was mostly localized in subtelomeric regions of chromosomes (except for chromosome 5) and also in pericentromeric regions of chromosomes 3,4 , and 5 .

In karyotypes of all studied $P$. sativum specimens, hybridization sites of $(\mathrm{AG})_{12}$ were clustered in the intercalary regions of both arms of all chromosome pairs. Besides, a polymorphic $(\mathrm{AG})_{12}$ site was revealed in the distal region of the long arm of chromosome 3 (Figure 3 ).

In nearly $50 \%$ of the studied F1-14 plants, multiple hybridization signals of the oligo-(GAA) ${ }_{9}$ probe were detected in the short arm of satellite chromosome 7 while only one (GAA), site was observed in karyotypes of F2-14, F116, and F2-16 plants and also control specimens (Figure 4). In some F1 and F2 plants (ISS-14 and 16), (GAA) 9 signals were also detected on chromosome 6 (Figures 3 and 4 ) which were absent in the control specimens.

Based on distribution patterns of the examined molecular cytogenetic markers, all chromosomes in the studied $P$. sativum plants were precisely identified (Figure 2). The karyograms of the control and experimental plant specimens ( $\mathrm{F} 1$ and F2 generations) as well as the generalized idiogram showing the chromosomal distribution of the examined markers were constructed (Figure 3).

In the studied $P$. sativum plants, significant chromosomal aberrations were not revealed with the exception of one F114 plant bearing a reciprocal translocation between chromosomes 2 and 3 (Figure 2).

\section{Discussion}

P. sativum is a valuable nutritive crop having considerable natural genetic diversity though the pea evolution from its wild ancestor to the cultivated species involved selection for thousands of years [45]. P. sativum is a genetically wellcharacterized species which has long been used as a classic model in genetic studies [45].

The pea karyotype has a relatively low chromosome number $(2 \mathrm{n}=14)$ and the chromosome lengths range from of 3 to $6 \mu \mathrm{m}[46,47]$. The genome of $P$. sativum is rather large $(1 \mathrm{C}=4.45 \mathrm{Gbp})$ [47], and repetitive sequences make up $50-60 \%$ of the total DNA $[45,48]$. Repetitive DNA is an important component of the plant genome that is involved in genome reorganization during evolution and adaptation $[34,49]$. It was shown that environmental stress factors could be responsible for quantitative changes in plant DNA (particularly, changes in satellite DNAs) [35]. Dynamic changes in the heterochromatin structure which occur during plant adaptation to a new environment can result in amplification of transposable elements as well as recombination events between repeats within satellite DNAs [50]. For instance, in Arabidopsis plants subjected to longterm heat stress, the increased level of transcription of satellite DNAs was observed [51]. These processes can induce structural genomic changes and formation of new structural domains and regulatory units [50]. Spaceflight-related stress 


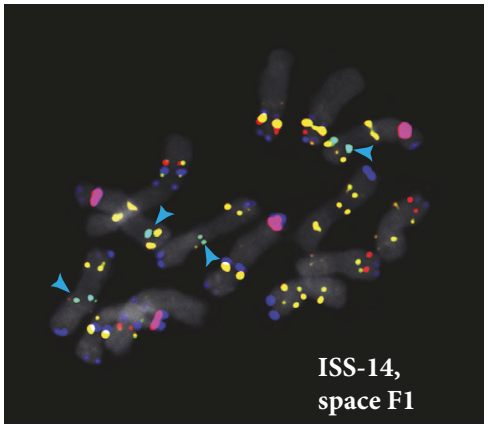

(a)

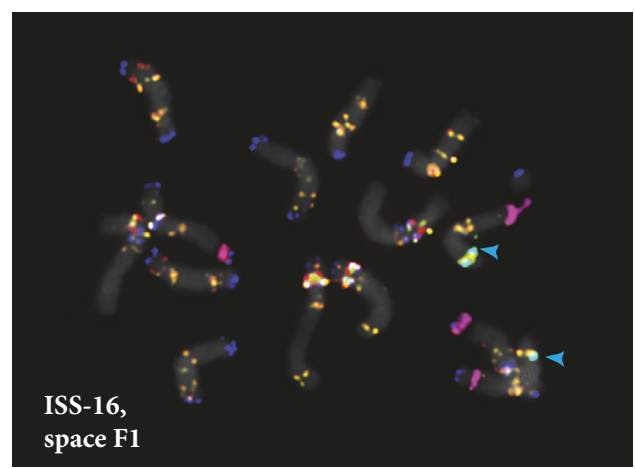

(d)

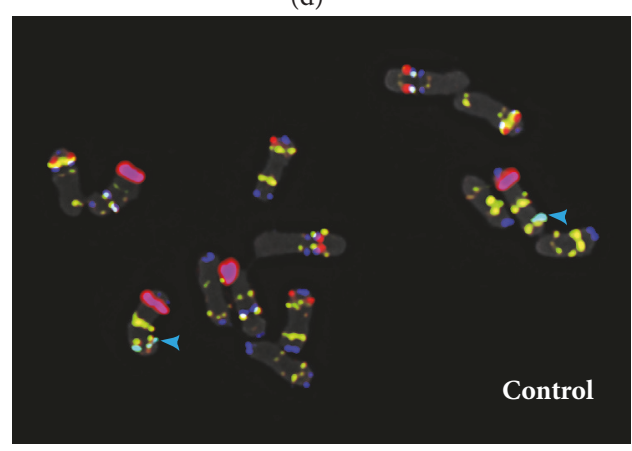

(e)

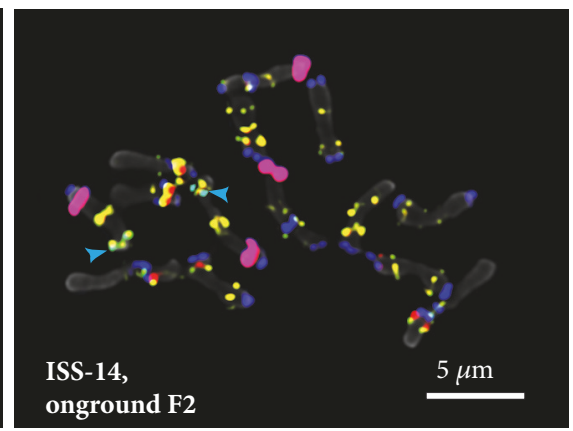

(b)

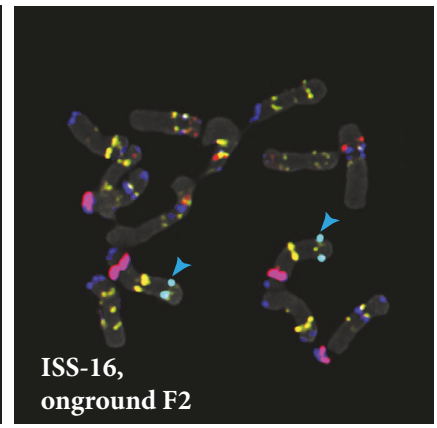

(c)

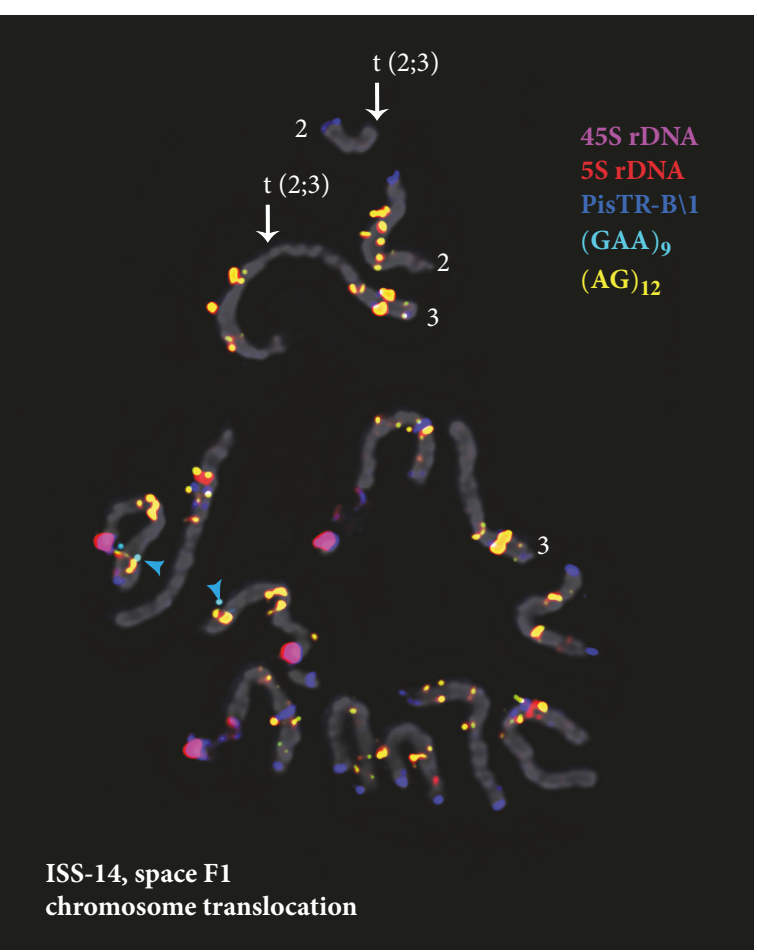

(f)

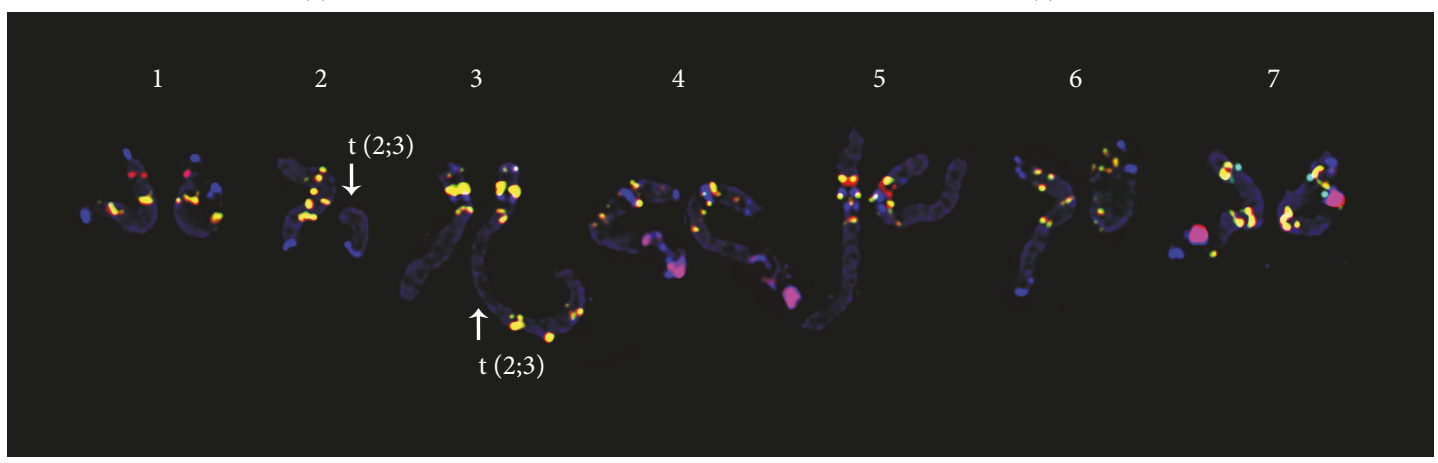

(g)

FIgURE 2: FISH-mapping of five different DNA repeated sequences on chromosomes of experimental and control P. sativum samples. Metaphase spreads of the F1-14 plant (a), F2-14 plant (b), F2-16 plant (c), F1-16 plant (d), control plant (e), F1-14 plant bearing translocation

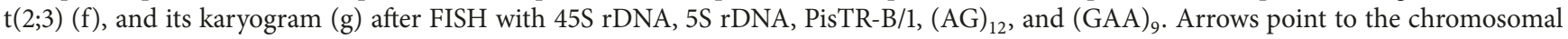
translocation. Heads of arrows point to (GAA), sites on chromosomes 6 and 7. The correspondent probes and their pseudocolours are specified on the right. Bar: $5 \mu \mathrm{m}$. 


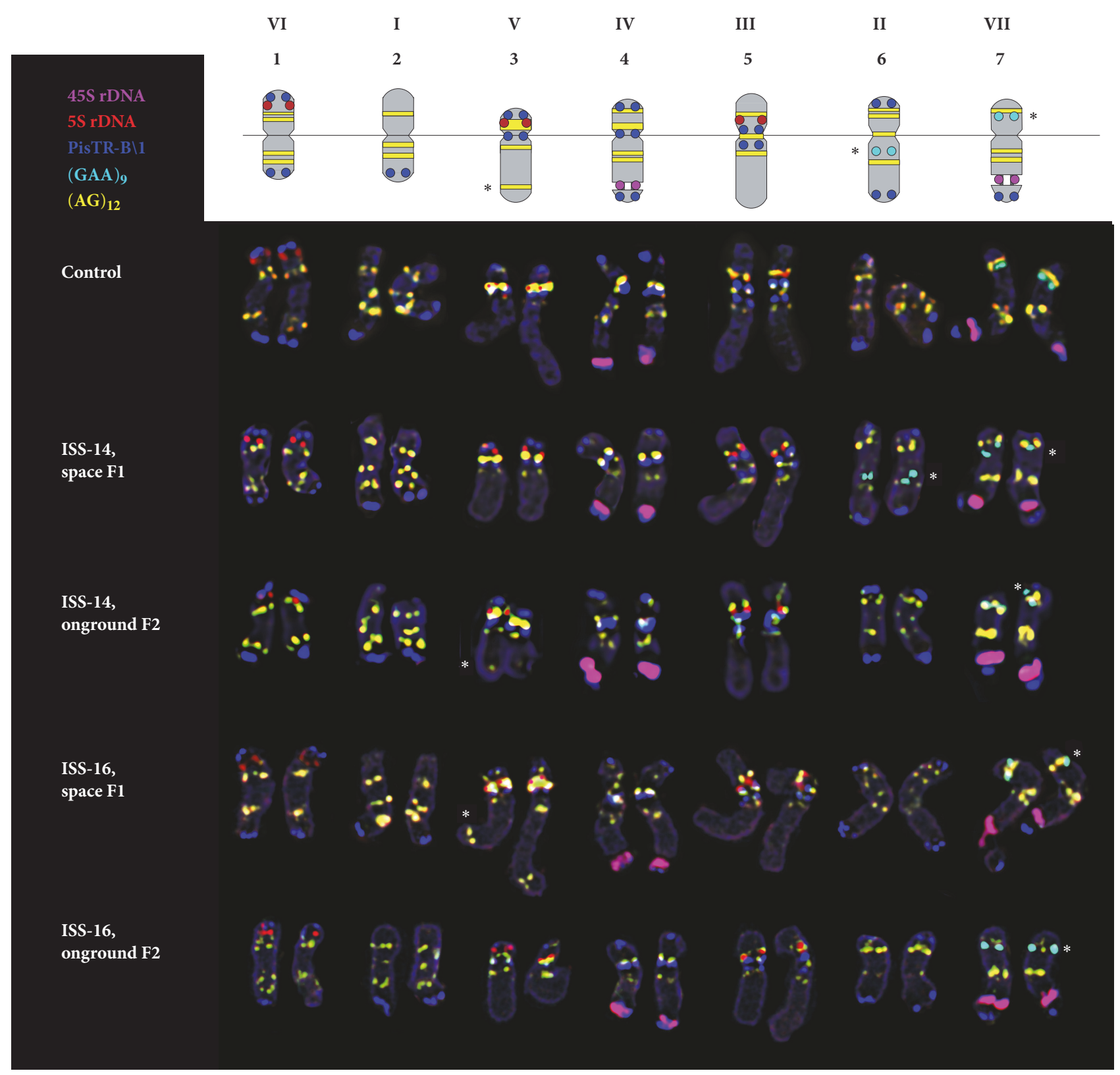

FIGURE 3: Generalized idiogram of $P$. sativum chromosomes showing the chromosomal distribution of the examined markers and karyograms of the control and experimental samples. Chromosome numbers and linkage groups are denoted with Arabic and Roman numerals, correspondingly. Asterisks indicate polymorphic $(\mathrm{GAA})_{9}$ and $(\mathrm{AG})_{12}$ sites. The correspondent probes and their pseudocolours are specified on the left.

factors can induce different genetic disorders in plants. For example, it was shown that space radiation resulted in various chromosomal aberrations and mitotic abnormalities in plants $[52,53]$. In this study, the presence of a chromosomal aberration in one F1-14 plant can be related to peculiarities of seed formation occurring on the mother plant under space environment which were described earlier $[4,6,7]$. Alternatively, it might be a result of long-term seed storage that could induce chromosomal aberrations [37, 54].

It was reported earlier that number of mono-, di-, tri-, tetra-, penta-, and hexa-nucleotide repeat motifs in genomes of different plant species could be species-specific [55]. A number of microsatellites (AAT)n, (AT)n, (GAA)n, and (AG) $n$ were found to be frequent in the pea genome [48]. In the present study, the use of a combination of two microsatellites $\left((\mathrm{GAA})_{9}\right.$ and $\left.(\mathrm{AG})_{12}\right)$ with a pea specific PisTR-B as well as $5 \mathrm{~S}$ and $45 \mathrm{~S}$ rDNA probes allowed us to identify all the pea chromosomes as well as perform the chromosome comparison of the plants grown from the "space grown" seeds with the plants of ground control. In the P. sativum plants examined here, chromosomal distribution of $45 \mathrm{~S}$ rDNA, $5 \mathrm{~S}$ rDNA, and PisTR-B/1 mainly corresponded to the patterns 


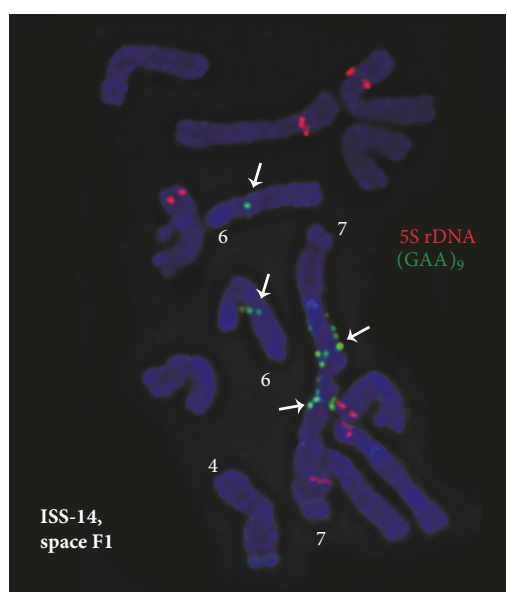

(a)

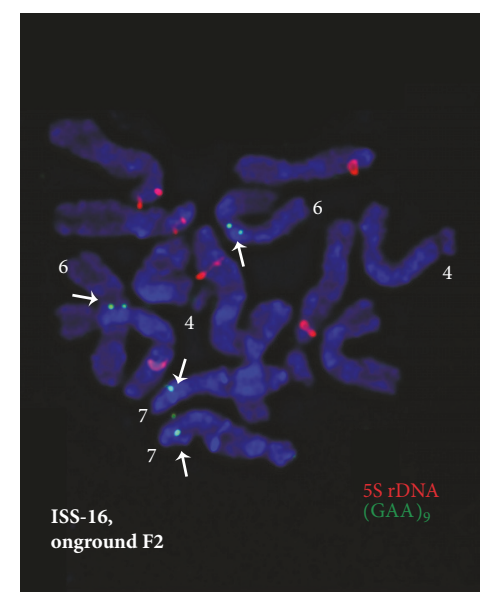

(c)

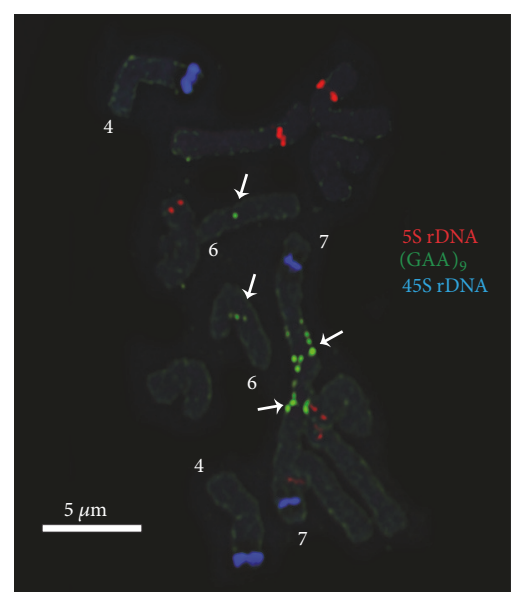

(b)

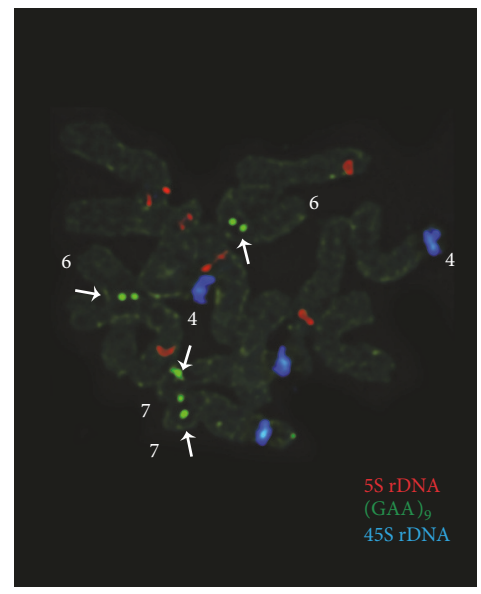

(d)

FIGURE 4: FISH-based localization of 45S rDNA, 5S rDNA, and (GAA) ${ }_{9}$ on the metaphase spreads of F1 (ISS-14) and F2 (ISS-16) $P$. sativum plants. Metaphase spread of a F1 pea plant (ISS-14) after FISH with 5S rDNA, (GAA) (a) and 45S rDNA, 5S rDNA, (GAA) ${ }_{9}$ (b). Metaphase spread of a F2 pea plant (ISS-16) after FISH with $5 \mathrm{~S} \mathrm{rDNA},(\mathrm{GAA})_{9}$ (c) and $45 \mathrm{~S} \mathrm{rDNA}, 5 \mathrm{~S}$ rDNA, (GAA) ${ }_{9}$ (d). Arrows point to the polymorphic $(\mathrm{GAA})_{9}$ sites on chromosomes 6 and 7. The correspondent probes and their pseudocolours are specified on the right. Bar: $5 \mu \mathrm{m}$.

reported earlier $[42,45,56]$ with the exception of the only report of four chromosome pairs bearing $5 \mathrm{~S}$ rDNA sites in the karyotype of one P. sativum variety [57] which is probably due to the intraspecific variability and/or particularity of that variety. Precise chromosome identification allowed us to specify the localization of the $(\mathrm{GAA})_{9}$ and $(\mathrm{AG})_{12}$ sites on $P$. sativum chromosomes.

In all pea specimens studied here (including the ground control), we observed a low level of polymorphism in chromosome distribution of $(\mathrm{AG})_{12}$ and PisTR-B/1. However, we revealed more sites of the oligo- $(A G)_{12}$ probe in karyotypes of the studied of $P$. sativum than it was reported earlier [57]. This might indicate the presence of the intraspecific variability in chromosome distribution of the $(\mathrm{AG})_{\mathrm{n}}$ motif in P. sativum. Moreover, in karyotypes of F1-14 plants, we observed multiple hybridization signals of $(\mathrm{GAA})_{9}$ on satellite chromosome 7 which were absent in the control plants. Besides, in karyotypes of some F1 and F2 plants (ISS-14 and ISS-16) additional (GAA) ${ }_{9}$ sites were also detected on chromosome 6 . Considering the fact that intraspecific polymorphism in chromosomal distribution of AG and GAA motifs was described earlier for other plants (e.g., Hordeum marinum and Brassica rapa ssp. chinensis) $[58,59]$, the detected changes might also be an example of intraspecific genomic polymorphism. Alternatively, they can be related to plant cell adaptive responses to spaceflightrelated stress factors. Microsatellites are shown to be involved in the processes of fast adaptation of plant populations to environmental changes and also phenotypic plasticity within and between generations, and gene-associated tandem repeats provide diverse variations promoting rapid development of new forms [31]. Some microsatellites act as cisregulatory elements which can be recognized by transcription factors. For instance, it was shown that (GA)n and (GAA)n 
repeats were included in promoters of several plant genes and participated in regulation of processes of transcription and translation [60-63].

Plant adaptation to spaceflight conditions is known to correlate with activation of genetic and epigenetic antistress mechanisms. Large-scale analyses of transcriptome in several plant species (B. rapa, H. vulgare) showed that spaceflightrelated stress factors led to oxidative stress in plants and caused an increase in expression of the genes related to abiotic and biotic stresses and also in production and activities of antioxidant enzymes [9, 10, 12]. Operating experience of hermetically sealed objects showed that artificial atmosphere is known to be a multicomponent mixture involving harmful micro impurities related to various structural classes [20,64], and an increased level of ethylene is considered to be a major cause of oxidative stress in plants $[1,5,14]$. For example, phytotoxic influence of ethylene $\left(1.1-2.0 \mathrm{mg} / \mathrm{m}^{3}\right)$, which was early detected in the air aboard the Space Station Mir, resulted in changes in the productivity and morphometric characteristics of dwarf wheat cultivated there [5]. Spaceflight-related stress factors might induce plant cell adaptive responses manifested at the genomic level as changes in a copy number of microsatellite motifs. In support of this view, changes in plant vegetation period were observed during the ISS-14. Unfortunately, the other karyotypic studies of plants grown from the "space" seeds are next to none. This issue needs further investigations as the "Lada" space greenhouse is too small in size to produce a great number of seeds.

\section{Conclusions}

Significant changes in distribution of the examined repeated DNAs in karyotypes of the "space grown" P. sativum plants as well as in F1 and F2 pea plants cultivated on Earth were not observed if compared with control plants. The revealed changes in chromosomal distribution of the oligo-(GAA) probe in karyotypes of F1 and F2 plants might be an example of intraspecific genomic polymorphism or related to plant cell adaptive responses to spaceflight-related stress factors.

Our findings suggest that, despite gradual total trace contamination of the atmosphere onboard the ISS associated with the extension of the space station operating life, exposure to the long-term spaceflight-related stress factors did not induce serious chromosome reorganizations in genomes of the "space grown" pea plants and generations of these plants cultivated on Earth.

\section{Data Availability}

All data used to support the findings of this study are included within the article.

\section{Conflicts of Interest}

The authors declare that the research was conducted in the absence of any commercial or financial relationships that could be construed as potential conflicts of interest.

\section{Authors' Contributions}

The present study was conceived and designed by Olga Yu. Yurkevich, Olga V. Muravenko, Tatiana E. Samatadze, Alexandra V. Amosova, Margarita A. Levinskikh, and Vladimir N. Sychev. Margarita A. Levinskikh provided plant materials. Oligonucleotide probes were synthesized by Sergei A. Surzhikov. Olga Yu. Yurkevich, Tatiana E. Samatadze, and Svyatoslav A. Zoshchuk carried out the FISH experiments. Olga Yu. Yurkevich, Olga V. Muravenko, Tatiana E. Samatadze, Alexandra V. Amosova, Margarita A. Levinskikh, and Olga B. Signalova analyzed the data. Olga Yu. Yurkevich, Olga V. Muravenko, Tatiana E. Samatadze, Margarita A. Levinskikh, Vladimir N. Sychev, Alexandra V. Amosova, and Sergei A. Surzhikov participated in preparing and writing the manuscript. Olga Yu. Yurkevich, Olga V. Muravenko, Alexandra V. Amosova, Margarita A. Levinskikh, Vladimir N. Sychev, Svyatoslav A. Zoshchuk, Tatiana E. Samatadze, and Olga B. Signalova performed the analysis with constructive discussions. All authors contributed to revising the manuscript. All authors have read and approved the final manuscript. Olga Yu. Yurkevich and Tatiana E. Samatadze contributed equally to this work.

\section{Acknowledgments}

This work was supported by the Program of Fundamental Research for State Academies (No. 0120136 3824) and Russian Foundation of Basic Research (No. 15-08-04564 and No. 1804-01091).

\section{References}

[1] M. E. Musgrave and A. Kuang, "Plant reproductive development during spaceflight," Advances in Space Biology and Medicine, vol. 9, pp. 1-23, 2003.

[2] V. De Micco, S. De Pascale, R. Paradiso, and G. Aronne, "Microgravity effects on different stages of higher plant life cycle and completion of the seed-to-seed cycle," The Journal of Plant Biology, vol. 16, no. 1, pp. 31-38, 2014.

[3] H. Q. Zheng, F. Han, and J. Le, "Higher plants in space: microgravity perception, response, and adaptation," Microgravity Science and Technology, vol. 27, no. 6, pp. 377-386, 2015.

[4] M. E. Musgrave, A. Kuang, Y. Xiao et al., "Gravity independence of seed-to-seed cycling in Brassica rapa," Planta, vol. 210, no. 3, pp. 400-406, 2000.

[5] M. A. Levinskikh, V. N. Sychev, T. A. Derendyaeva et al., "Analysis of the spaceflight effects on growth and development of Super Dwarf wheat grown on the Space Station Mir," Journal of Plant Physiology, vol. 156, no. 4, pp. 522-529, 2000.

[6] M. A. Levinskikh, V. N. Sychev, O. B. Signalova et al., "Some characteristics of plant seeds formed in microgravity," Aerospace and Environmental Medicine, vol. 36, pp. 32-35, 2002.

[7] B. M. Link, J. S. Busse, and B. Stankovic, "Seed-to-seed-toseed growth and development of Arabidopsis in microgravity," Astrobiology, vol. 14, no. 10, pp. 866-875, 2014.

[8] T. Hoson, K. Soga, K. Wakabayashi et al., "Growth stimulation in inflorescences of an Arabidopsis tubulin mutant under microgravity conditions in space," The Journal of Plant Biology, vol. 16, no. 1, pp. 91-96, 2014. 
[9] E. I. Shagimardanova, O. A. Gusev, V. N. Sychev et al., "Expression of stress response genes in barley Hordeum vulgare in a spaceflight environment," Journal of Molecular Biology, vol. 44, no. 5, pp. 734-740, 2010.

[10] A. L. Paul, A. K. Zupanska, D. T. Ostrow et al., "Spaceflight transcriptomes: Unique responses to a novel environment," Astrobiology, vol. 12, no. 1, pp. 40-56, 2012.

[11] A. K. Zupanska, F. C. Denison, R. J. Ferl, and A.-L. Paul, "Spaceflight engages heat shock protein and other molecular chaperone genes in tissue culture cells of Arabidopsis Thaliana," American Journal of Botany, vol. 100, no. 1, pp. 235-248, 2013.

[12] M. Sugimoto, Y. Oono, O. Gusev et al., "Genome-wide expression analysis of reactive oxygen species gene network in Mizuna plants grown in long-term spaceflight," BMC Plant Biology, vol. 14, no. 1, article 4, 2014.

[13] R. J. Ferl, J. Koh, F. Denison, and A.-L. Paul, "Spaceflight induces specific alterations in the proteomes of arabidopsis," Astrobiology, vol. 15, no. 1, pp. 32-56, 2015.

[14] J. G. Carman, P. Hole, F. B. Salisbury, and G. E. Bingham, "Developmental, nutritional and hormonal anomalies of weightlessness-grown wheat," Life Sciences in Space Research, vol. 6, pp. 59-68, 2015.

[15] V. N. Sychev, M. A. Levinskikh, and I. G. Podolsky, "Biological component of life support systems for a crew in long-duration space expeditions," Acta Astronautica, vol. 63, no. 7-10, pp. 1119$1125,2008$.

[16] M. A. Levinskikh, V. N. Sychev, I. G. Podolsky et al., "Modern problems of creation of the autotrophic link of perspective lifesupport systems of space crews," Aviakosmicheskaia i Ekologicheskaia Meditsina, vol. 47, pp. 91-92, 2013.

[17] V. N. Sychev, M. A. Levinskikh, S. A. Gostimsky, G. E. Bingham, and I. G. Podolsky, "Spaceflight effects on consecutive generations of peas grown onboard the Russian segment of the International Space Station," Acta Astronautica, vol. 60, no. 4-7, pp. 426-432, 2007.

[18] S. A. Gostimsky, M. A. Levinskikh, V. N. Sychev et al., "The study of the genetic effects in generation of pea plants cultivated during the whole cycle of ontogenesis on the board of RS ISS," Russian Journal of Genetics, vol. 43, no. 8, pp. 869-874, 2007.

[19] A. V. Zelenin, T. E. Samatadze, M. A. Levinskikh et al., "The cultivation of peas on the board the International Space Station did not induce changes in their karyotypes," Pisum Genetics, vol. 41, pp. 46-47, 2009.

[20] A. A. Pakhomova, D. S. Ozerov, D. S. Tsarkov et al., "Description of the chemical make-up of air on the International space station," Aviakosmicheskaia i Ekologicheskaia Meditsina, vol. 51, no. 1, pp. 58-64, 2017.

[21] H. Zhang, Z. Tao, H. Hong et al., "Transposon-derived small RNA is responsible for modified function of WRKY45 locus," Nature Plants, vol. 2, pp. 16016-16023, 2016.

[22] J. Wang, S. T. Jia, and S. Jia, "New insights into the regulation of heterochromatin," Trends in Genetics, vol. 32, no. 5, pp. 284-294, 2016.

[23] P. Neumann, H. Yan, and J. Jiang, "The centromeric retrotransposons of rice are transcribed and differentially processed by RNA interference," Genetics, vol. 176, no. 2, pp. 749-761, 2007.

[24] I. Djupedal and K. Ekwall, "Epigenetics: heterochromatin meets RNAi," Cell Research, vol. 19, no. 3, pp. 282-295, 2009.

[25] Z. Lippman and R. Martienssen, "The role of RNA interference in heterochromatic silencing," Nature, vol. 431, no. 7006, pp. 364-370, 2004.
[26] A. V. Probst and O. M. Scheid, "Stress-induced structural changes in plant chromatin," Current Opinion in Plant Biology, vol. 27, pp. 8-16, 2015.

[27] J. S. P. Heslop-Harrison and T. Schwarzacher, "Organisation of the plant genome in chromosomes," The Plant Journal, vol. 66, no. 1, pp. 18-33, 2011.

[28] B. J. Merritt, T. M. Culley, A. Avanesyan, R. Stokes, and J. Brzyski, "An empirical review: characteristics of plant microsatellite markers that confer higher levels of genetic variation," Applications in Plant Sciences, vol. 3, no. 8, p. 1500025 , 2015.

[29] A. T. M. Bagshaw, "Functional mechanisms of microsatellite DNA in eukaryotic genomes," Genome Biology and Evolution, vol. 9, no. 9, pp. 2428-2443, 2017.

[30] R. G. Hodel, M. C. Segovia-Salcedo, J. B. Landis et al., "The report of my death was an exaggeration: a review for researchers using microsatellites in the 21st century," Applications in Plant Sciences, vol. 4, no. 6, p. 1600025, 2016.

[31] Y. C. Li, A. B. Korol, T. Fahima, and E. Nevo, "Microsatellites within genes: structure, function, and evolution," Molecular Biology and Evolution, vol. 21, no. 6, pp. 991-1007, 2004.

[32] G.-F. Richard, A. Kerrest, and B. Dujon, "Comparative genomics and molecular dynamics of DNA repeats in eukaryotes," Microbiology and Molecular Biology Reviews, vol. 72, no. 4, pp. 686-727, 2008.

[33] J. Shi, S. Huang, D. Fu et al., "Evolutionary dynamics of microsatellite distribution in plants: insight from the comparison of sequenced brassica, arabidopsis and other angiosperm species," PLoS ONE, vol. 8, no. 3, p. e59988, 2013.

[34] S. Siljak-Yakovlev, "Evolutionary implications of heterochromatin and rDNA in chromosome number and genome size changes during dysploidy: a case study in Reichardia genus," PLoS ONE, vol. 12, no. 8, Article ID e0182318, 2017.

[35] C. A. Cullis, "The Environment as an active generator of adaptive genomic variation," in In Plant adaptations to stress environments, H. R. Lerner, Ed., pp. 149-160, Marcel Dekker, New York, NY, USA, 1999.

[36] A. V. Amosova, L. V. Zemtsova, Z. E. Grushetskaya et al., "Intraspecific chromosomal and genetic polymorphism in Brassica napus L. detected by cytogenetic and molecular markers," Journal of Genetics, vol. 93, no. 1, pp. 133-143, 2014.

[37] M. Murata, E. E. Roos, and T. Tsuchiya, "Mitotic delay in root tips of peas induced by artificial seed aging," Botanical Gazette, vol. 141, no. 1, pp. 19-23, 1980.

[38] J. A. Ozga, D. M. Reinecke, N. R. Knowles, and P. Blenis, "Characterization of the loss of seedling vigor in pea (Pisum sativum L.)," Canadian Journal of Plant Science, vol. 84, no. 2, pp. 443-451, 2004.

[39] O. Y. Yurkevich, I. V. Kirov, N. L. Bolsheva et al., "Integration of physical, genetic, and cytogenetic mapping data for cellulose synthase (CesA) genes in flax (Linum usitatissimum L.)," Frontiers in Plant Science, vol. 8, article 1467, 2017.

[40] W. L. Gerlach and J. R. Bedbrook, "Cloning and characterization of ribosomal RNA genes from wheat and barley," Nucleic Acids Research, vol. 7, no. 7, pp. 1869-1885, 1979.

[41] W. L. Gerlach and T. A. Dyer, "Sequence organization of the repeating units in the nucleus of wheat which contain $5 \mathrm{~S}$ rRNA genes," Nucleic Acids Research, vol. 8, no. 21, pp. 4851-4865, 1980.

[42] P. Neumann, M. Nouzová, and J. Macas, "Molecular and cytogenetic analysis of repetitive DNA in pea (Pisum sativum L.)," Genome, vol. 44, no. 4, pp. 716-728, 2001. 
[43] T. H. N. Ellis and S. J. Poyser, "An integrated and comparative view of pea genetic and cytogenetic maps," New Phytologist, vol. 153, no. 1, pp. 17-25, 2002.

[44] P. Neumann, D. Pozárková, J. Vrána, J. Doležel, and J. Macas, "Chromosome sorting and PCR-based physical mapping in pea (Pisum sativum L.)," Chromosome Research, vol. 10, no. 1, pp. 63-71, 2002.

[45] P. Smýkal, G. Aubert, J. Burstin et al., "Pea (Pisum sativum L.) in the genomic era," Agronomy, vol. 2, no. 4, pp. 74-115, 2012.

[46] J. Greilhuber and I. Ebert, "Genome size variation in Pisum sativum," Genome, vol. 37, no. 4, pp. 646-655, 1994.

[47] J. Doležel and J. Greilhuber, "Nuclear genome size: Are we getting closer?" Cytometry Part A, vol. 77, no. 7, pp. 635-642, 2010.

[48] J. Macas, P. Neumann, and A. Navrátilová, "Repetitive DNA in the pea (Pisum sativum L.) genome: comprehensive characterization using 454 sequencing and comparison to soybean and Medicago truncatula," BMC Genomics, vol. 8, article 427, 2007.

[49] S. I. S. Grewal and S. Jia, "Heterochromatin revisited," Nature Reviews Genetics, vol. 8, no. 1, pp. 35-46, 2007.

[50] Ž. Pezer, J. Brajković, I. Feliciello, and D. Ugarkovć, "Satellite DNA-mediated effects on genome regulation," Genome Dynamics, vol. 7, pp. 153-169, 2012.

[51] M. Tittel-Elmer, E. Bucher, L. Broger et al., "Stress-Induced Activation of Heterochromatic Transcription," PLoS Genetics, vol. 6, no. 10, p. e1001175, 2010.

[52] A. D. Krikorian, "Plants and somatic embryos in space: what have we learned?" Gravitational and Space Biology Bulletin, vol. 11, no. 2, pp. 5-14, 1998.

[53] N. G. Platova and V. M. Petrov, "Biological estimation of space radiation effect by way of plant bio-object example," Aviakosmicheskaia i Ekologicheskaia Meditsina, vol. 47, pp. 117118, 2013.

[54] W. M. Waterworth, C. M. Bray, and C. E. West, "The importance of safeguarding genome integrity in germination and seed longevity," Journal of Experimental Botany, vol. 66, no. 12, pp. 3549-3558, 2015.

[55] H. Sonah, R. K. Deshmukh, A. Sharma et al., "Genome-wide distribution and organization of microsatellites in plants: an insight into marker development in Brachypodium," PLOS ONE, vol. 6, no. 6, Article ID e21298, 2011.

[56] T. E. Samatadze, O. V. Muravenko, N. L. Bolsheva, A. V. Amosova, S. A. Gostimsky, and A. V. Zelenin, "Investigation of chromosomes in varieties and translocation lines of pea Pisum sativum L. by FISH, Ag-NOR, and differential DAPI staining," Genetika, vol. 41, no. 12, pp. 1665-1673, 2005.

[57] J. Fuchs, M. Kühne, and I. Schubert, "Assignment of linkage groups to pea chromosomes after karyotyping and gene mapping by fluorescent in situ hybridization," Chromosoma, vol. 107, no. 4, pp. 272-276, 1998.

[58] A. Carmona, E. Friero, A. D. Bustos, N. Jouve, and A. Cuadrado, "The evolutionary history of sea barley (Hordeum marinum) revealed by comparative physical mapping of repetitive DNA," Annals of Botany, vol. 112, no. 9, pp. 1845-1855, 2013.

[59] J. S. Zheng, C. Z. Sun, S. N. Zhang et al., "Cytogenetic diversity of simple sequences repeats in morphotypes of Brassica rapa ssp. chinensis," Frontiers in Plant Science, vol. 7, article 1049, 2016.

[60] M. L. C. Vieira, L. Santini, A. L. Diniz, and C. D. F. Munhoz, "Microsatellite markers: What they mean and why they are so useful," Genetics and Molecular Biology, vol. 39, no. 3, pp. 312328, 2016.
[61] L. Zhang, K. Zuo, F. Zhang et al., "Conservation of noncoding microsatellites in plants: Implication for gene regulation," BMC Genomics, vol. 7, article no. 323, 2006.

[62] J. Reneker, E. Lyons, G. C. Conant et al., "Long identical multispecies elements in plant and animal genomes," Proceedings of the National Acadamy of Sciences of the United States of America, vol. 109, no. 19, pp. E1183-E1191, 2012.

[63] S. Kumar and S. Bhatia, "A polymorphic (GA/CT)n- SSR influences promoter activity of Tryptophan decarboxylase gene in Catharanthus roseus L. Don," Scientific Reports, vol. 6, no. 1, Article ID 33280, 2016.

[64] L. N. Mukhamedieva and V. V. Bogomolov, "Characteristic of toxic risks of air pollution by chemical admixtures aboard the piloted orbital stations," Aviakosmicheskaia i Ekologicheskaia Meditsina, vol. 43, pp. 17-23, 2009. 


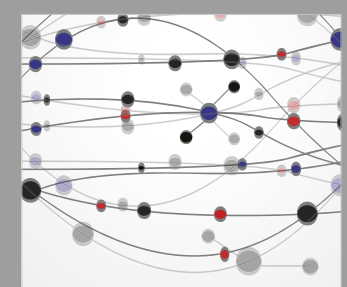

The Scientific World Journal
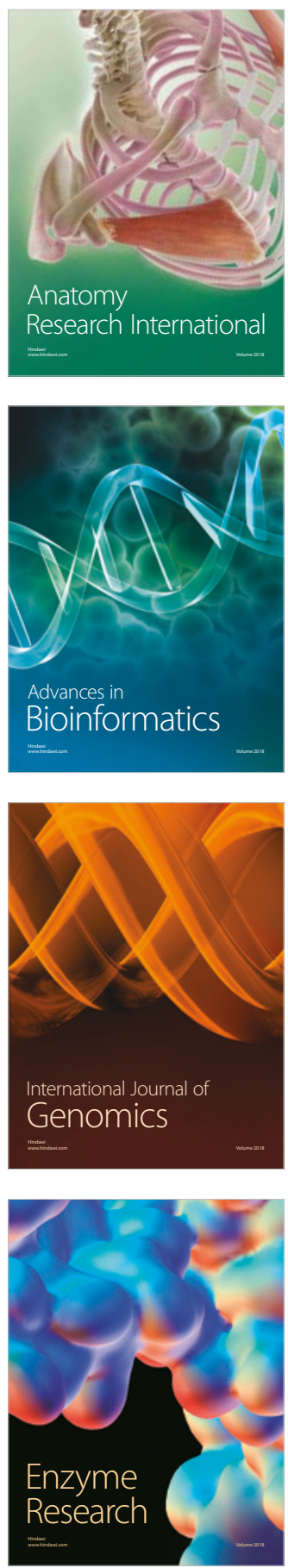
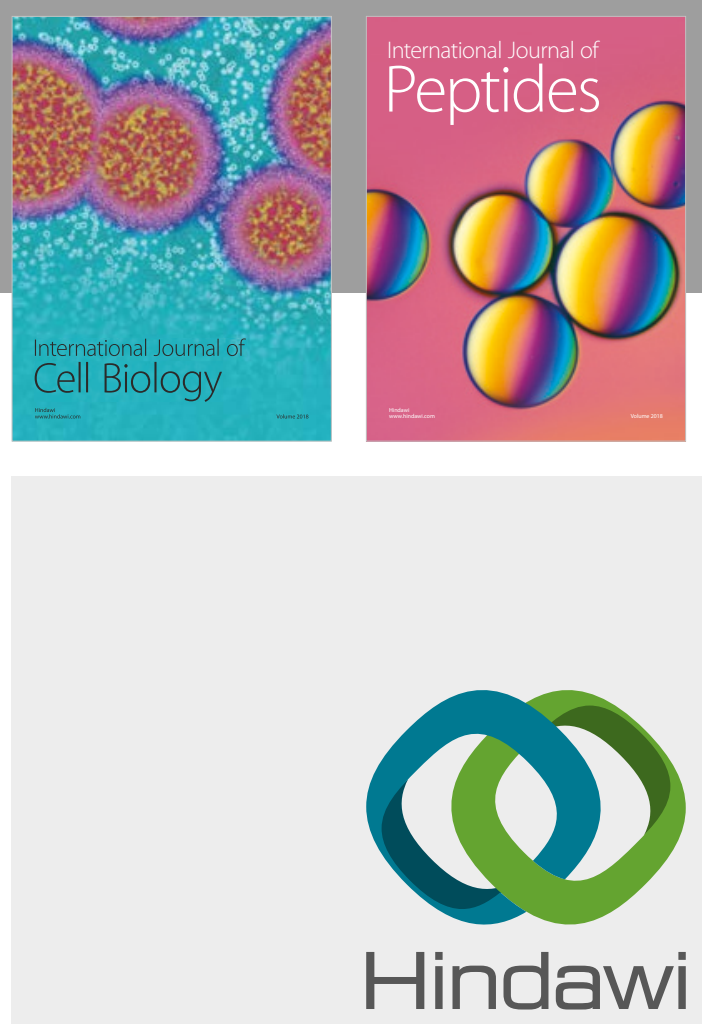

Submit your manuscripts at

www.hindawi.com
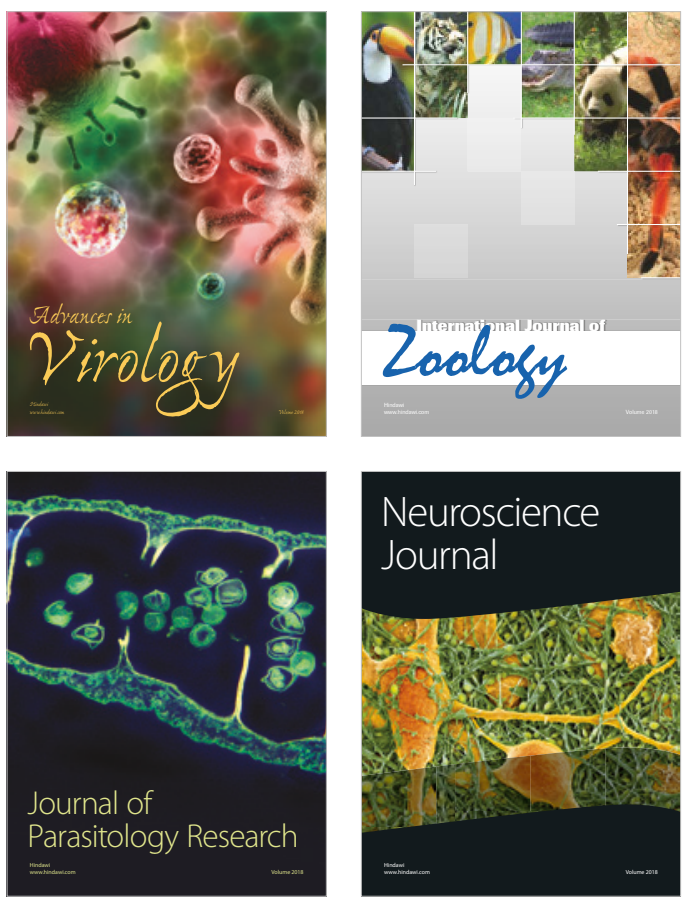
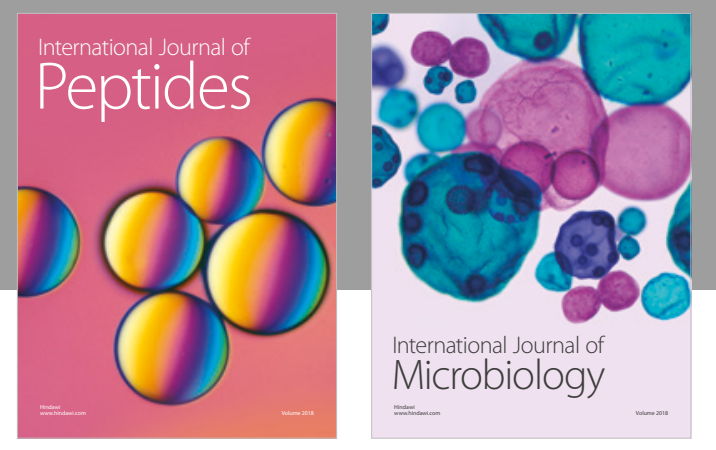

nternational Journal of Microbiology
Journal of
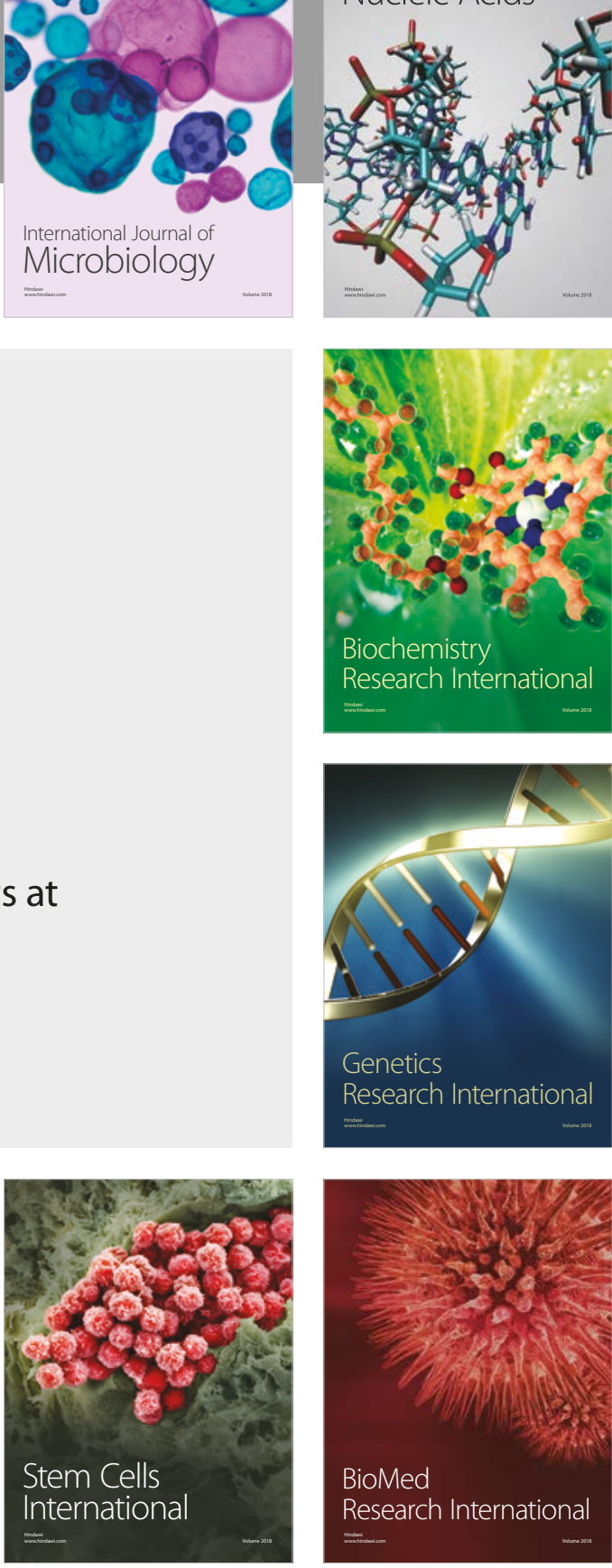
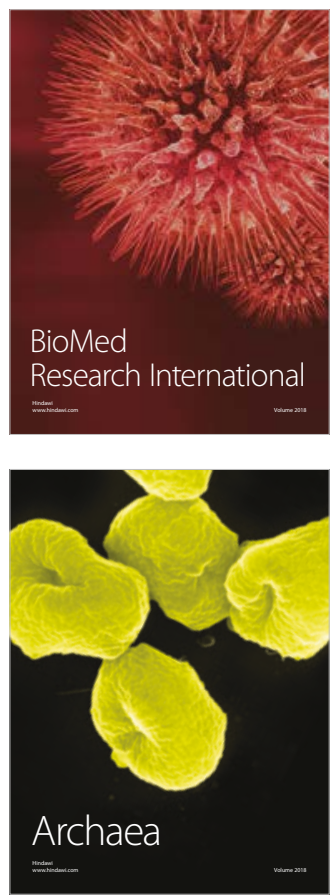